El cambio de $r$ a $l$ en Santo Domingo no sería ni de refuerzo ni de debilitamiento; sería, únicamente, un proceso de neutralización en final de sílaba. $\mathrm{Si}$, por el contrario, nos fijamos en la modificación de $n$ a $\eta$ notamos un proceso que no se debe especificar como de neutralización, ya que $\eta$ no contrasta en la representación subyacente con ninguna otra nasal en posición final. Es, por tanto, un proceso de debilitamiento. Por otra parte, como ya dijimos, la conversión de $r$ a $l$ ejemplifica una neutralización porque ambas existen y contrastan en posición inicial de sílaba en interior de palabra como en / pára/-/pála/, y en posición final, como se observa en forma fonética [káldo] que proviene de /kárdo/ o /káldo/.

De acuerdo a lo dicho, no tendríamos ninguna razón para rechazar la hipótesis de Houlihan: "Word-final neutralizations may be strengthening processes. Word-final non-neutralizations are weakening processes" (op. cit., p. 111).

Con ella no se invalida y tampoco se reajusta la jerarquía de fuerza que se ha establecido en (7). Damos, por tanto, apoyo a la hipótesis de Houlihan en tanto no aparezcan en un dialecto o en una lengua reglas de no neutralización al final de sílaba que sean un proceso de fuerza.

En resumen, un proceso que englobe una modificación de fonones al final de sílaba puede ser de debilitamiento en la medida que se le compare con una jerarquía consonántica de fuerza que lo determine $\mathrm{y}$ defina. $Y$, finalmente, no todos los procesos finales de sílaba son necesariamente de debilitamiento.

Rafael NúÑez Cedeño

University of New Hampshire.

\title{
OVIEDO A MEDIA LUZ
}

Recia personalidad la de Gonzalo Fernández de Oviedo, alias de Sobrepeña. Recia y longeva personalidad la del Néstor de los cronistas de Indias, según la hermosa y acertada expresión de Eugenio Asensio. Había nacido en Madrid, y en 1477 o 1478, vacilación impuesta por el hecho de que en esto de calcular su edad, nuestro cronista no las cortaba en el aire, y no se conoce ningún testimonio documental sobre ella. Si el año exacto de su nacimiento se mantiene reacio e incierto', no ocurre lo

1 No quiero andarme por las ramas y dejar suponer que malsino la memoria de Oviedo, o que arremeto contra algún critico en particular. Un solo texto autógrafo de Oviedo basta para iluminar la problemática cuestión. En la dedicatoria al futuro Felipe II de sus Quinquagenas de la nobleza de España, nuestro cronista escribió de su mano: "A diez días del mes de Enero de 1555 años de la natalidad de Christo nuestro Redemptor, de mi propria e cassada [sic] mano, e seyendo complidos 77 años de mi edad". Esto nos debe retrotraer al año de 1478 , lo que queda refrendado de inmediato por los cómputos que hace acerca de cuándo y cuántos años tenía cuando 
mismo con el nombre de su patria chica, ya que nuestro cronista tuvo siempre a timbre de gloria, de su primera a su última obra, el anunciar en voz bien alta su cualidad de madrileño. En su primera obra en salir a la estampa (Don Claribalte, 1519), inmediatamente después de ese alias de Sobrepeña, que por largo tiempo tuvo perplejos a los críticos, y en ese mismo prólogo, se continúa con la nueva aclaración de que el autor era "vecino de la noble villa de Madrid". Y en la última obra que la cansada mano del cronista pudo escribir, sus Quinquagenas de la nobleza de España (terminadas trece meses antes de su muerte, ocurrida el 27 de junio de 1557), dejó este postrer y exaltado testimonio, que conviene copiar por extenso dado su interés doblemente genealógico (cito por mi edición, t. 1, p. 311):

Como ninguno sin ser ingrato deue oluidar su patria, áme parescido que yo sería culpado si entre tanta moltitud e diuersidad de historias e buenas materias como vo acomulando en esta segunda rima de mis Quinquagenas oluidase a Madrid, syendo vna villa tan noble e famosa en España, e como yema de toda ella puesta en la mitad de su circunsferencia. En la qual yo nascí de padres e progenitores naturales del principado de Asturias de Ouiedo, procreados en vn pequeño pueblo que se dize Borondes, de la filegresía de San Miguel de Vascones y concejo de Grado, notorios hijosdalgo e de nobles solares.

Entre uno y otro extremo temporal menudean los ejemplos de su ufanía madrileña, a flor de piel, a flor de labios y a flor de pluma. Imposible regatearle la distinción de haber sido el primer escritor madriñelista, y digo escritor así, sin calificativos, como bien lo merece alguien que practicó la novela, la poesía, la historia, las memorias... Si Dámaso Alonso designó a don Juan Hurtado de Mendoza (veinte años menor que Oviedo) como "poeta madrileñista, latinista y francesista", Oviedo le sobrepasa, y con mucho, en sus dotes literarias, y si no fue destacado latinista, ni siquiera francesista, su italianismo le deja bien parado, y su americanismo no es para ser parangonado con el de nadie, y le coloca en una situación de primus inter pares.

La muerte de nuestro ardoroso madrileñista, ya octogenario, o poco menos, no ocurrió en sus queridos Madriles, ni siquiera en la Península, como por mucho tiempo se creyó, sino en el puesto con que le había recompensado el emperador, de alcaide de la fortaleza de Santo Domingo, allá en las lejanísimas Antillas. Por largos años la crítica se despistó

entró a servir en la casa real. Pero en el explicit de la misma obra se lee con claridad meridiana, dada la bellísima caligrafía de Fernández de Oviedo: "Acabé de escribir de mi mano este famoso tractado de la nobleza de España domingo primero día de Pasqua de Pentecostés XXIII de mayo de 1556 años, Lavs Deo, y de mi edad 79 años". Y esta vez, sin lugar a dudas, debemos retrotraernos a 1477. De los tres preciosos y fornidos volúmenes que forman el autógrafo de estas Quinquagenas, por muchísimos años sólo se conoció el primero, publicado en pésima edición por Vicente de la Fuente (Madrid, 1880). En años recientes he publicado estas Quinquagenas, en forma que explico con detalle más adelante.-Con mucho tino me observa Antonio Alatorre que Oviedo nació sin duda en 1477, pero no antes del 10 de enero, con lo que se compagina todo. Así, el 10 de enero de 1555 pudo decir que tenía 77 años "complidos", mientras que el 23 de mayo del año siguiente tenía ya 79. 
al seguir las huellas de José Amador de los Ríos, en su estudio biográfico de nuestro cronista, y le supuso muerto en Valladolid, cuando desde hace más de medio siglo se nos ha alertado que Oviedo murió en el Nuevo Mundo, en ese mundo que al matar su cuerpo, nimbó de imperecedera fama su memoria.

Los azares que llenaron la vida encuadrada por esos topes temporales surgieron con la premura y frecuencia del agua de manantial, y si estuviese bien documentada la biografía de Oviedo bastarían para llenar un grueso mamotreto. Pero hay que reconocer la verdad, y ella nos dice que dicha vida está, fundamentalmente, mal conocida. Valga, como botón de muestra, la vacilación recién consignada acerca de la fecha precisa de su nacimiento. Sobre sus padres sólo se pueden emitir opiniones, algunas más aceptables y atractivas que otras, pero ninguna con respaldo documental. Muy poco mejora la cuestión al tratar de los años formativos de nuestro cronista, porque allí la carestía documental se complica ante el hecho de que la única autoridad asequible para enhebrar hechos, viajes, anécdotas, son las aseveraciones del propio Oviedo. Los largos y capitales años de la experiencia americana salen un poco mejor medrados, tanto por la existencia, ahora sí, de un acopio documental, como por la proliferación del anecdotario personal y de la bien marcada veta autobiográfica del cronista Oviedo. Pero, así y todo, el crítico no se puede dormir en los laureles conquistados por sus predecesores. En realidad, no hemos avanzado tanto en el camino de la verdad biográfica como para no reconocer la sustancial veracidad de palabras que estampó José Toribio Medina allá en 1898, cuando, después de elogiar el estudio de Amador de los Ríos sobre la vida de Oviedo, añadió: "Puede todavía estudiarse mucho más registrando el Archivo de Indias, que guarda muchos e interesantes documentos relativos al verdadero primer cronista de Indias, algunos de los cuales nos proponemos dar a conocer en nuestro Vasco Níñez de Balboa"2.

La vida de Oviedo, sin embargo, se puede trazar a grandes rasgos, siempre y cuando éstos no sean de mayor finura ni delicadeza. El futuro cronista se educó en la corte de los Reyes Católicos, en calidad de paje del príncipe don Juan, cuya temprana e inesperada muerte hizo vacilar a la Historia. A pesar de las repetidas afirmaciones de Oviedo al respecto, se duda de que su calidad haya sido efectivamente la de paje, y se le supone, más bien, "mozo de cámara"'. Pero la muerte del príncipe en octubre de 1497 deshizo su casa y los sueños de toda España. Oviedo quedó a la deriva y surgió en Italia, donde peregrinó y sirvió de 1499 a 1502, de Milán a Sicilia. Al perder a un nuevo y

2 J. T. Mrdina, Biblioteca Hispanoamericana (1493-1810), Santiago de Chile, 1898, t. 1 , p. 149.

3 El propio Oviedo escribe lo siguiente en el Libro de la cimara real del prin. cipe don Juan $e$ officios de su casa $e$ servicio ordinario, manuscrito autógrafo, biblioteca del Escorial, ms. e.iv.8, fol. 14 r: "Pajes del Principe fueron los hijos de los grandes e prinçipales caualleros de aquestos reynos". Sigue la lista onomástica de los pajes y, desde luego, Oviedo no figura entre ellos. Es posible que Oviedo distinguiese, en forma implícita, entre paje 'criado' y paje del Principe. En tal caso, habrá sido un paje de tantos, uno del montón. 
querido amo (don Fadrique, rey de Nápoles), vuelve a España. Siguen años inciertos, que después de una década parecen apuntarle nuevamente hacia Italia. Pero la rueda de la Fortuna da nueva vuelta, se vienen abajo todos los planes y en 1514 Oviedo navega hacia las Indias y no hacia el humanismo italiano. Viaja como "veedor de las fundiciones de oro de la Tierra Firme" en la expedición de Pedrarias Dávila, que tristes páginas escribió en la Historia.

De ahora en adelante los vendavales de América rigen la vida de Gonzalo Fernández de Oviedo, que bien pronto se comienza a definir en una sucesión de viajes transatlánticos que vienen a puntuar su labor historiográfica. De Tierra Firme pasa a Santo Domingo, y de "veedor de las fundiciones de oro" a alcaide de la fortaleza isleña, y todo resaltado por la aureola intelectual de ser ahora cronista oficial de Indias, título que no hay que confundir con el de "cronista mayor de Indias", posterior y ajeno por completo a la vida de Oviedo. Las estancias en España servirán para publicar algo (muy poco, según se verá) de lo compuesto en Indias, y al mismo tiempo para acallar y apabullar críticos, para dirimir jurisdicciones intelectuales y territoriales, para recabar mercedes... Y así le asaltó la muerte, de regreso en su alcaidía dominicana, en el año de 1557, a los ochenta de su edad, mes más o menos.

Insisto en que muchas son las sombras que quedan en el retrato de Oviedo, que se pueden esfumar ante una investigación archivística llevada a cabo con método, tesón y fortuna. Pero los rasgos esenciales del retrato sí se pueden trazar ahora con mucha más precisión y firmeza que la que pudo utilizar José Amador de los Ríos en su "Vida y escritos de Gonzalo Fernández de Oviedo", compuesta hace casi ciento treinta años. En este sentido, es justo destacar la labor de Juan Pérez de Tudela Bueso, quien, en su trabajo, asimismo titulado "Vida y escritos de Gonzalo Fernández de Oviedo", trató de poner al día y armonizar los resultados de la investigación de la crítica ${ }^{4}$. Hasta el día de hoy, y que yo sepa, este primero y meritorio intento no ha tenido émulos.

Es verdad inconcusa que la obra de Fernández de Oviedo es de dimensiones ciclópeas, pero, puesto ya en el brete de especificar cuáles obras del cronista madrileño son fácilmente asequibles a la mayoría de los investigadores, cualquier crítico se verá en figurillas. Porque, la verdad sea dicha, de esa obra ciclópea conocemos una parte bien pequeña. Es algo así como lo que se dice de la proverbial masa del iceberg, que al flotar exhibe sólo la quinta parte de su altura. Pero antes de pasar adelante, la justicia impone la mención de una nueva y valiosísima obra crítica. Me refiero al muy reciente libro, póstumo, por desgracia, al menos en su traducción española, de ANTONEllo Gerbi, La natura. leza de las Indias nuevas. De Cristóbal Colón a Gonzalo Fernández de

4 El trabajo de Amador fue el prólogo de su edición de la Historia general y natural de las Indias, cuatro volúmenes (Madrid, 1851-1855); el de Pérez de Tudela cumple las mismas funciones en su edición de la misma obra de Oviedo, Biblioteca de Autores Españoles, tomos 117-121. 
Oviedo ${ }^{5}$. El título puede parecer un poco engañoso, pero el primer centenar y medio de páginas sí está dedicado a recoger reacciones ante la nueva naturaleza americana por parte de descubridores, viajeros y cronistas, de Colón a Giovanni de Verrazzano. La parte del león de este elegante trabajo se la lleva, sin embargo, el estudio de la vida y la obra de Oviedo (páginas 149-477). Mas de inmediato debo precisar. La biografía de Gerbi no añade nada nuevo, ni era su intención hacerlo, al mismo tiempo que se centra, en forma particular, en dos momentos: los años italianos y la redacción de la Historia. Y esto nos trae al ver. dadero y superlativo valor del trabajo de Gerbi, donde se demuestra el verdadero fin de la grandiosa máquina montada por el americanista italiano: un estudio incomparable de dicha Historia, de todos sus ingredientes y de todas sus repercusiones. Aquí luce bien el dominio imperial del tema de la conquista intelectual de América que tuvo Antonello Gerbi.

Así como la labor biográfica de Gerbi nunca estuvo asestada hacia nuevos asedios documentales, de la misma manera su crítica literaria tampoco estuvo supeditada por los inéditos que constituyen la mayor parte de la obra de Oviedo, como queda dicho. El fino y penetrante análisis de Gerbi se circunscribe siempre a lo impreso, y hace caso omiso de lo demás. Ésta, en consecuencia, se presenta como buena ocasión para pasar revista a la obra total de Oviedo, para discriminar entre lo impreso y lo inédito; de lo impreso, qué textos se pueden mejorar a base de inéditos, y de éstos últimos cuáles son autógrafos y cuáles no. Así tendremos mejor idea de la configuración total de este extraordinario iceberg literario que constituyen los opera omnia de Gonzalo Fernández de Oviedo.

A tales efectos sigue una lista de la producción literaria del cronista madrileño que no guarda ningún orden particular. E1 cronológico es imposible de guardar en forma sistemática ya que dicha cronología (de composición y de publicación, esta última en los pocos casos en que es aplicable) está sin establecer; cualquier otro orden no guarda relación con el problema planteado. Me apoyo en la bibliografía que trae Pérez de Tudela Bueso al final de su largo estudio ya citado, con las adiciones dictadas por el tiempo transcurrido y el estado de la investigación actual. También manejo a Daymond Turner, Gonzalo Fernández de Oviedo y Valdés: An annotated bibliography, Chapel Hill, 1966.

5 El original italiano dice así: La natura delle Indie nove. (Da Cristoforo Colombo a Gonzalo Fernández de Oviedo), Riccardo Ricciardi Editore, Milano-Napoli, 1975. La versión española la sacó el Fondo de Cultura Económica (México, 1978), y se debe a la pluma maestra de Antonio Alatorre, quien ya había traducido la otra gran obra de Gerbi, La disputa del Nuevo Mundo. Historia de una polémica, 1750-1900, que fue publicada por la misma gran casa editorial mexicana en 1960. La traducción de Alatorre de la obra que me ocupa tiene dos claras ventajas sobre el original italiano: la primera es el valiosísimo apéndice literario-musical sobre el Cancionero del Duque de Calabria (es de esperar que bien pronto se abandone la poco ilustradora denominación de Cancionero de Upsala), y la segunda es un muy cuidado indice analítico debido a los hijos del traductor. Mucho menos evidentes, pero muy efec. tivas, son otras mejoras de esta traducción: la bibliografía, cl sistema de citas, adiciones elegantes, claras y precisas, etc. 
I. Libro del muy esforçado e inuencible Cauallero de la Fortuna propiamente llamado don Claribalte. Valencia, Juan Viñao, 1519. Reeditado en Sevilla, Andrés de Burgos, 1545, según demostró Gerbi. De la edición valenciana hay un hermoso facsímile de la Real Academia Española (Madrid, 1956). Lo estudié yo, a mi vez, en un trabajo que no conoció Gerbi, pero sí Alatorre, quien lo puso entre sus adiciones: "El novelista Gonzalo Fernández de Oviedo y Valdés, alias de Sobrepeña", Anales de Literatura Hispanoamericana, I (Madrid, 1972), recogido ahora en mi Dintorno de una época dorada (Madrid, 1978), pp. 101-117).

II. Esta es vna muy notable y moral epistola que el muy illustrisimo señor Almirante de Castilla embió al actor de las sobre dichas quinquagenas, hablando de los males de Spaña y de la causa dellos con la respuesta del mismo auctor, Biblioteca Nacional de Madrid, ms. 7.075, no es autógrafo, y al margen dice: "Esto se escribía en el año 1524". No utiliza Gerbi este intercambio de epístolas entre don Fadrique Enríquez, Almirante de Castilla, y Oviedo; lo publiqué yo en mi trabajo, "Dos preocupados del Siglo de Oro", $A L M, 13$ (1975), 113-163.

III. Relación de lo sucedido en la prisión del rey Francisco de Francia, Biblioteca Nacional de Madrid, ms. 8.756; publicado en la Coleccción de documentos inéditos para la historia de España, 38 (Madrid, 1861), 404-492. El original no es autógrafo. Lo menciona Gerbi muy de pasada. No ha sido estudiado todavía, y bien lo merece porque da todos los indicios de ser torso de una obra mucho mayor, que redactaba de regreso en Santo Domingo.

IV. Oviedo de la natural historia de las Indias. Toledo, Remón de Petras, 1526. Múltiples reediciones modernas, por lo general bajo el título de Sumario de la natural y general historia de las Indias, que figura en el folio Iv de la editio princeps. Hay edición facsímil (issued in honor of Sterling A. Stoudemire (Chapel Hill, 1969).

V. Libro primero del blasón. Tratado general de todas las armas. La copia manuscrita que se conserva en la biblioteca de la Real Academia de la Historia, Madrid, se conserva inédita y sin estudiar. En una época parece que se interesó en su publicación Juan de Mata Carriazo.

VI. Epilogo real, imperial y pontifical. Original autógrafo en la Biblioteca Nacional de Madrid, ms. 6224, sin publicar ni estudiar. El códice está lleno de tachaduras y correcciones, y es ilegible en buena parte.

VII. Libro de la cámara real del Príncipe don Juan. El original autógrafo se custodia en la biblioteca del Escorial, ms. e-IV-8. El siglo pasado fue editado, en forma bien poco competente, por J. M. Escudero de la Peña (Madrid, Bibliófilos Españoles, 1870). El autógrafo fue transcrito con cuidado, y con buenas notas, en la tesis doctoral de Jon Vincent Blake (University of North Carolina, 1957), hecha bajo mi dirección. Es de esperar que pronto se publique. 
VIII. Batallas y quinquagenas. Hay muchas copias manuscritas (Biblioteca Nacional de Madrid, Biblioteca Real, Biblioteca de la Real Academia de la Historia), todas incompletas y ninguna merecedora de entera fe. El original eran cuatro inmensos volúmenes que nunca se han publicado ni estudiado. He descubierto el voluminoso autógrafo de la segunda parte (más de mil folios), y lo tengo en curso de publicación. Como es obra importantísima en la bibliografía de Oviedo, volveré sobre ella más abajo. Por el momento baste decir que ha sido obra muy citada, nunca leída en su totalidad, y casi nunca ni siquiera en forma parcial.

IX. Libro de linajes y armas. La copia manuscrita del siglo xvi se conserva en la biblioteca de la Real Academia de la Historia, signatura antigua C-24, actual $9 / 247$. No se ha publicado ni estudiado, y apenas si se ha visto citado.

$\mathrm{X}$. Las quinquagenas de los generosos e illustres e no menos famosos reyes, principes, duques, marqueses y condes e caballeros e personas notables de España. Los tres grandes y hermosos volúmenes autógrafos se custodian en la Biblioteca Nacional de Madrid, signaturas 2.217 a 2.219. Los he publicado yo, en forma de copiosísimo florilegio (el original, de publicarse íntegro, sería de precio prohibitivo y de lectura intragable), y bajo el título de Las memorias de Fernández de Oviedo, dos volúmenes (Chapel Hill, 1974), con copiosas notas. También, más abajo, volveré sobre esta obra.

XI. Historia general y natural de las Indias. En vida de Oviedo salieron las siguientes ediciones, todas incompletas: La historia general de las Indias (Sevilla, Juan Cromberger, 1535); Crónica de las Indias (Salamanca, Juan de Junta, 1547) ; Libro XX de la segunda parte de la general historia de las Indias (Valladolid, Francisco Fernández de Córdoba, 1557). La primera edición completa fue la del benemérito José Amador de los Ríos, cuatro volúmenes (Madrid, Real Academia de la Historia, 1851-55); en la biblioteca de dicha Academia se conservan todavía los originales autógrafos que usó Amador, pero nunca se han cotejado metódicamente con el impreso. El texto de Amador ha sido copiado repetidas veces, una de ellas en la edición, ya citada, de Juan Pérez de Tudela Bueso. De entonces acá se han vuelto a encontrar los originales autógrafos de Oviedo de los libros IV, VI, VII, IX, XI, XXXII y XXXVII, que se custodian en la Huntington Library, de San Marino, California. Difieren ampliamente de los textos impresos por Amador de los Ríoș y en ellos trabaja el joven investigador chileno José Anadón, en la actualidad catedrático en University of Notre Dame, en los Estados Unidos.

XII. Catálogo Real de Castilla y de todos los reyes de las Españas... hasta el año de Cristo de MDXXXII años. El voluminoso autógrafo se conserva en la biblioteca del Escorial, signatura H-j-7. Desde la época en que lo usó Gonzalo Argote de Molina en su Nobleza de Andalucía (Sevilla, Fernando Díaz, 1588), el tratado no se ha vuelto a utilizar ni estudiar. 
XIII. Laberinto de amor. Se conocen cédulas reales de 1526 que conceden privilegio a Oviedo para la impresión de una obra de tal título, que sería "el tratado llamado Laberinto de amor de Juan Boccaccio, de la lengua toscana en romance castellano". Obra de tal título, traducción de Boccaccio, salió en Sevilla, Andrés de Burgos, 1546; aunque anónima, se ha atribuido al canónigo toledano don Diego López de Ayala, aunque la cuestión no está muy bien fundamentada, y buena falta hace un estudio a fondo de todo ello.

XIV. Regla de la vida spiritual y secreta theologia. Sevilla, Dominico de Robertis, 1548. Esta traducción del italiano también sale anónima, y el único ejemplar conocido está en la riquísima biblioteca de mi querido y admirado Eugenio Asensio, quien nos dio breve perfil de la obra, retocado por Antonio Alatorre en sus adiciones a Gerbi, op. cit., pp. 189190. El original italiano es de Pietro da Lucca, Regule de la vita spirituale et secreta teologia (Bolonia, 1507; Venecia, 1516). No se ha reimpreso la traducción de Oviedo.

Ahora si, creo, estamos en mejores disposiciones para dar un nuevo asalto a la obra de Oviedo, que por sus dimensiones, como se puede ver, bien se puede denominar casi inexpugnable fortaleza. En esta nueva empresa, belicosa e intelectual (como fue el sino del propio Oviedo), las funciones de adalid le corresponden a Antonello Gerbi con su macizo y extraordinario libro La naturaleza de las Indias nuevas. En el siglo xx la obra de Gerbi en relación a la comprensión del pensamiento de Gonzalo Fernández de Oviedo cumple análogo desempeño a la obra de José Amador de los Ríos en el siglo xix en relación a la posibilidad de lectura de dicha obra. Y obsérvese bien que ambas obras están asestadas al estudio de la misma y señera enciclopedia histórica de Oviedo, su Historia general y natural de las Indias. Insisto en ello porque quiero dejar bien claro el valor del inmenso empuje que ha dado Gerbi al estudio de la Historia general de Oviedo. Si ahora pongo algunas cortapisas a su método no es en desmedro de la memoria de Antonello Gerbi, y no quiero que nadie, nunca, lo pueda entender así. De mortuis nil nisi bonum sólo expresa parte del respeto y admiración que he sentido siempre por la obra del gran historiador desaparecido. Mis observaciones, que seguirán de inmediato, son un primer pago en la gran deuda y compromiso intelectuales que hemos contraído con la memoria de Gerbi todos los que visitamos la historia hispana del siglo xvi.

Ya he dicho que Gerbi trabajó sólo a base de la obra publicada de Fernández de Oviedo, y tal actitud, desde un punto de vista humano, es comprensible. Esperar a que se publique todo lo inédito escrito por Oviedo es algo así como esperar a las calendas griegas, al menos al paso a que procede la crítica ovetense. Que una sola persona publique lo inédito parece ser pensar en lo exensado. Evidentemente, hay que pensar en un trabajo de equipo, pero tal grupo no se ha formado todavía. iQuiera Dios que pronto veamos tal equipo en funciones! Que se publiquen pronto los volúmenes y volúmenes que forman el corpus inédito de Oviedo es lo menos que exigen nuestras disciplinas. Se conoce el pa- 
radero de casi todos los inéditos de Oviedo, ¿qué se espera? IManos a la obra!

Yo he descubierto el paradero del segundo volumen autógrafo de las Batallas y Quinquagenas de Gonzalo Fernández de Oviedo, obra de incomparable importancia para la historia de los siglos xv y xvı. Con su publicación soñó José Amador de los Ríos, para coronar de tal manera la labor tan benemérita que estaba llevando a cabo la Real Academia de la Historia, que había publicado la Historia general y estaba en trance de publicar las Quinquagenas de la nobleza de España del cronista madrileño. Pero por diversos motivos el empeño fracasó, y como fruto de tantos desvelos sólo quedó un raquítico torso ${ }^{6}$. Se conservan numerosos manuscritos de las Batallas, y ya dejé constancia de ello, pero ninguno se acerca, ni de lejos, a la soberbia y voluminosisima obra que nos describió el propio Oviedo. Copio de sus Quinquagenas de la nobleza de España:

Hame aprouechado mucho salir con este tractado o Quinquagenas, otras que escriuo más largamente dialogando de la nobleza e casas principales de España en que digo sus fundadores, e rrentas, e armas, e sus genealogías, e muchas historias e casos interuenidos a aquellos de quien allí tracto (en cuatro grandes volúmines), y en cada casa de quien tratto comienço en el señor della que yo vi, e dialogando se traen a conseqüencia los ascendientes e descendientes. Obra es en que yo he gastado mucha parte de mis días y noches, y no la he acabado por dos cosas: la vna porque he tenido esperança de yr a morir a España para perficionar algunos pasos en lo moderno de aquellas casas que se acomulan en la 3 parte de las Quinquagenas dialogales. Lo otro que me ha detenido es una promesa que hizo el corcmista Florián Docampo, donde dize en su prohemio de la primera parte de la Crónica de España, que de quatro libros [que] se imprimieron en Çamora e acabaron a XV de diziembre de 1543 años, que el tercero e último volumen, que avn no ha salido, tractará entre otras cosas vna relación de las parentelas y linajes..., y pues ha doze años que le atiendo y no vemos que cumple su promesa, no entiendo de dexar de proseguir lo començado, que a la verdad esto de las armas en España ha menester mucha vigilancia para escriuirlo bien (en mis Memorias de Gonzalo Fernández de Oviedo, II, 542-543).

Y mucho más adelante amplía e insiste nuestro cronista madrileño en el plan de estas Batallas que tantos cuidados le provocaban:

Mis diálogos de las casas de España illustres e de nobles linajes e famosos caualleros en que ha quescriuo desde el año de 1535. Y están escriptas más mill y quinientas hojas, y es obra en que se tracta de las perssonas e fundadores de sus mayoradgos e casas, e de sus genealogías e armas. E comienço siempre en el cauallero que vi e conosci en la casa de que tracto, e dialogando tráense a conseqüencia los ascendientes e descendientes de los tales. En lo qual ay muchas hystorias peregrinas e onrrosas para nuestra

- Amador de los Ríos dejó constancia del trabajo efectuado para la publicación de las Batallas en un informe que salió póstumo, "Sobre la publicación de las Batallas y Quinquagenas del capitán Gonzalo Fernández de Ovieđo", BAH, I (1877.1879), 209-217. Un poco más abajo vuelvo sobre las Quinquagenas de la nobleza de España. 
nasción. $\mathrm{Y}$ esperando vna promesa e aviso de armas e linajes quel dotto maestro Florián de Ocampo prometió en la primera parte que anda empresa de su Cosmographia [sic], que dize que en la última parte de aquella su obra la veremos, he hecho vna pausa de doze años que ha que le espero por me avisar arrimado a él de lo que podría ser que yo no sé. Pero ya veo que tanto se tarda su socorro ques bien que sin él acabe mis diálogos lo mejor que yo pudiere (op. cit., II, 599-600).

De los "quatro grandes volúmines" que encierran tales tesoros de noticias histórico-genealógico-económicas yo he descubierto el segundo volumen, autógrafo, cuyo título reza así: Libro segundo que trata de las armas apostólicas del saneto Padre e de las órdenes Militares de caualleros e de las Órdenes sagradas a quienes están atribuidas e en costumbre propias armas $e$ insignias. Sólo este volumen consta de 1026 folios, todos en la letra de nuestro historiador y pendolista, tan primorosa como pequeña, lo que nos debe dar mejor idea de las ciclópeas dimensiones de la obra total, si Dios me depara hallar los otros tres "gruesos volúmines". De todas maneras, estoy en plenas tareas de transcripción, anotación y publicación del tomo descubierto, todo esto con una muy amplia y generosísima ayuda del National Endowment for the Humanities del gobierno de los Estados Unidos.

Todo esto lo menciono como un toque de atención a las nuevas promociones que se dediquen al estudio de Gonzalo Fernández de Oviedo. Bien pronto el canon accesible a cualquier lector interesado en su obra quedará aumentado por sus voluminosas, capitales y autógrafas Batallas. Al mismo tiempo, el lector debe tomar cuenta de que hay accesible un buen texto del Libro de la cámara del Principe don Juan, muy superior al de Escudero de la Peña, ya mencionado. Asimismo, se debe recordar que el intercambio de epístolas "sobre los males de España", entre Oviedo y el Almirante de Castilla, fue publicado por mí en el Anuario de Letras. $\mathrm{Y}$ cuando se estudie la personalidad intelectual, literaria y espiritual del almirante de Castilla don Fadrique Enríquez, se habrá revelado la talla de una figura prócer, cuya importancia caló mucho más hondo que la de ser gobernador del reino cuando las Comunidades de Castilla.

Queda por revelar, ahora, el destino de las Quinquagenas de la nobleza de España, otra de las grandes obras de Oviedo, y que por casi un siglo se mantuvo inédita en sus dos terceras partes. Queda dicho que la obra consta de tres manuscritos autógrafos custodiados en la B.N.M. La Real Academia de la Historia, con el noble impulso adquirido por los esfuerzos de José Amador de los Ríos, decidió publicar, después de la Historia general, estas Quinquagenas, y confió la empresa a otro académico, Vicente de la Fuente. Éste publicó, en grueso infolio, el primer volumen del autógrafo, con mínimo aparato, y allí feneció la empresa. Lo cual no fue de lamentar, porque la transcripción adolece de errores gravísimos, por omisión y comisión. Dicho primer tomo salió, a expensas de la Real Academia de la Historia, en Madrid y en 1880. El interés por las Quinquagenas decayó de inmediato, y los tres preciosos tomos autógrafos volvieron a languidecer, casi mortecinos (o bien, muertos de 
la risa), en los anaqueles de la Biblioteca Nacional. Así las cosas, me deparó la suerte intervenir en la cuestión, y ahora, por economía, lo más directo será copiar algo de lo que imprimí en los preliminares de mi edición (t. 1, pp. 10-11) :

Hace mucho tiempo me propuse una edición paleográfica solvente de los tres tomos de las Quinquagenas, debidamente anotados, pero pronto ciertas graves consideraciones me hicieron modificar la naturaleza del proyecto. En primer lugar, un rápido vistazo al tomo publicado por La Fuente bastará para convencer al más incrédulo lector de que las Quinquagenas, en su volumen total, son de lectura absolutamente indigesta. Es que la composición de las Quinquagenas me trae a la memoria, en forma irresistible, el recuerdo de Orbaneja, aquel pintor de Ubeda que interrogado acerca de lo que pintaba contestaba: "Lo que saliere" (Quijote, II, 3). De la misma manera compuso Oviedo las Quinquagenas, a lo que saliese. El plan anunciado en el título de la obra no pasa de la primera página, para ser entonces sustituido por los caprichos y divagaciones de un anciano. En consecuencia, todo lo que sea caprichosa divagación se puede omitir, sin desmedro de lo que en sentido literal se puede entender por Quinquagenas de la nobleza de España, vale decir, los elogios de los nobles españoles que conoció Oviedo. Yo creo que una acertada definición de las Quinquagenas sería llamarlas las memorias de un gárrulo y memorioso anciano. Dada esta definición, entendí yo que mi primera obligación editorial era efectuar una poda a fondo, que eliminase todas (o casi todas) las muestras de gárrula ancianidad, pero que mantuviese intactos los múltiples ejemplos de la tenaz memoria cle un hombre extraordinario, por lo que había visto, por lo que habia viajado, y por lo que había vivido. Resultado inmediato: el inmenso volumen de las Quinquagenas originales se redujo a la mitad, a los dos tomos que el lector tiene entre manos, que, de todas maneras, ya está bien en cuanto a tamaño. Mi criterio podador ha sido, e insisto en ello para aclarar, mantener integras las memorias vitales de Oviedo, quiero decir, todos aquellos asnectos de las Quinauagenas que podemos considerar respaldados por las vivencias del autor. Por ello me sentí obligado a cambiar el título de la obra.

Por consiguiente, en Chapel Hill y en 1974, publiqué en dos volúmenes el meollo autobiográfico-histórico-anecdótico de las mentadas Quinquagenas de la nobleza de España, con un título más apropiado, dadas las circunstancias: Las memorias de Gonzalo Fernández de Oviedo. En esta empresa y en su ocasión, asimismo tuve el apoyo del benemérito National Endowment for the Humanities, en la forma de generosa ayuda de costa. Esta obra del gran cronista madrileño es un verdadero cajón de sastre, más aún que cualquiera otra de las suyas. El propio Gerbi (op. cit., pp. 446-454) reconoce esto en el breve pero acertado estudio que le dedica a base del primer volumen; aquel tan elegante como poco de fiar que publicó Vicente de la Fuente el siglo pasado.

La restricción que se había impuesto Gerbi de trabajar sólo sobre lo impreso, se suma en esta ocasión al hecho de que mi edición de las Quinquagenas, con el nuevo título de Memorias, no le llegó a las ma. nos en la ocasión de redactar su monografía. Por estos dos sencillos motivos el americanista italiano se negó más sazonados frutos para su 
investigación y crítica. No pienso hacer un florilegio de textos que podria haber usado Gerbi para precisar más su investigación acerca de Oviedo como observador de la sociedad y la naturaleza, ya sea en España, en Italia, o en Indias. Cualquier lector puede hacer uso, y matizar esas observaciones según su escuela y opinión. No quiero dejar de amenizar estas páginas, sin embargo, $\mathrm{y}$ al efecto copiaré el desenlace de una larga anécdota italiana de Fernández de Oviedo.

Se trata del año del Jubileo de 1500 y es pontífice en Roma Alejandro VI. Su hijo, César de Borja, es el terror de Italia y en ese año ha vuelto triunfante a Roma, adonde le llegan noticias de la prisión del Duque de Milán, Ludovico Sforza, por las tropas de Luis XII de Francia. En la Ciudad Santa los franceses inician ruidosos festejos a los gritos de "¡Francia, Francia! ¡Milán, Milán! ¡Don César, don César!” Oviedo, que fue testigo, y hasta quizá actor en estos acontecimientos, narra que los españoles allí estantes, ofendidos y amoscados, comienzan una imprevista degollina de franceses. Ahora dejo la palabra a Oviedo, en mi transcripción (ed. cit., t. 2, pp. 632-633), ya que el texto estuvo inédito hasta ese momento:

E estuuvo en gran peligro Rroma porque como al Duque le dixeron que los españoles avían muerto los que es dicho, él se armó a gran priesa $\mathrm{e}$ quiso dar forma como los españoles muriesen, e juró públicamente a Dios que no le avía de quedar compañón o turma de español aquel día... Tuuo el Duque de Valentinoes buen tiento entre su desatino, y determináronse cinco o seys capitanes, ombres de hecho y que le avían muy bien seruido en la guerra de la Rromaña, vno de los quales, y el más viejo y de mucha expiriencia, se dezía Sancho de Valdonzellas. Los quales, como les dixeron quel Duque se armaua a gran priesa, fueron a él a palacio, e el Sancho de Valdonzellas le dixo: "Señor, estos capitanes que aquí veys nos venimos a despedir de vuestra Excelencia porque no somos para castrados, pero hazemos vos saber quel que nos quitare las turmas le dolerá la cabeça, y que V.S. no deués [sic] de encargaros dese oficio porque no es para vos. Y quédese vuestra Excelencia con Dios, y embiadnos a esos carniceros". E boluiéronle las espaldas. Oydo esto, el Duque de enojo se le saltauan las lágrimas, e díxose que si él se alargara en palabras, como algunas vezes estando con enojo lo solía hazer, que yvan allí ombres que pusieran las manos en el Duque, e al tiempo que se salían dixo el Sancho de Valdonzellas, quel Duque lo oyó: "Yo no puedo creer quel Duque dixese tal desuarío. Pero hágós saber que avnque no lo dixese le hará mal prouecho que se diga que lo dixo". E súpose que con lágrimas se desarmó e se rretruxo en su cámara. $\mathbf{E}$ todos los españoles de su casa le dexaron a él e avn al Papa, en especial los ombres de guerra, lo qual sintieron mucho.

Dada la importancia de los años italianos de Oviedo en su formación intelectual, y hasta espiritual, bien calibrada por Gerbi, anécdotas como la precedente no tienen precio. Porque dicha narración encierra las reacciones de un español en Italia ante las actividades imperialistas (cesaristas es adjetivo más adecuado, en más de un sentido) de otro español en la misma península. Hay una actitud de clara condena por parte de Oviedo, que remata con estos tres estruendosos y muy descriptivos latinismos: "Fue vn ombre ingrato e superbísimo e bendicatiuo" 
(Memorias, t. 2, p. 634). Los motivos para tal condenación no son difíciles de indagar, si se tiene en cuenta el hecho de que los mismos años presencian en Italia la política expansionista de los Reyes Católicos (eni rigor; de Fernando V, el Rey Católico), ilustre víctima de la cual sería el último amo italiano de Oviedo, el rey Fadrique de Nápoles a pesar de la política antagónica de César de Borja. Quizás en estos años comienza la siembra de las semillas de ese imperialismo integral que exhibirá continuamente, muchos años más tarde y ya en plena flor, la obra toda del Oviedo maduro.

El intercambio de epístolas entre Gonzalo Fernández de Oviedo y don Fadrique Enríquez, Almirante de Castilla, que publiqué en el Anuario de Letras, como queda dicho, presenta otros problemas e ilustra otros aspectos del vasto mapa intelectual de nuestro cronista. Escritas en 1524, dichas epístolas obedecen a una triste realidad española y que todavía, en dicho año, se podía tocar con el dedo. Me refiero a las revueltas de las Comunidades, a esa "primera revolución moderna", según el sentir de José Antonio Maravall, que desasosegó al nuevo emperador Carlos $\mathrm{V}$ tanto como a sus súbditos peninsulares. La cuestión que se pone sobre el tapete ahora, en consecuencia, es la de las relaciones recíprocas entre imperio, soberano y vasallos, todo encuadrado dentro del marco del humanismo cristiano, que pronto tornasola toda la obra de Oviedo, y al que estaba empeñosamente dedicado, en su vida y en sus obras, el Almirante don Fadrique. En palabras del propio Oviedo en su epístola:

Si el imperio de nuestro príncipe con su continua presencia y deuido honor gozar y perfeccionar se puede, esto es lo que más al decoro y honor de nuestra Spaña conuiene, y desto como de vna de las grandezas della nos deuemos gozar, y glorificar a la diuina clemencia y bondad por tan honrra nos hauer dado (ed. cit., p. 139).

Los autógrafos de la Historia general y natural de las Indias de Oviedo que se conservan en la californiana Huntington Library presentan problemas de muchos tipos, por cierto, y todos tendrán que ser considerados por las nuevas promociones para integrarlos, bien sopesados, en ese todo Oviedo que, esperanzadamente, creo divisar en lontananza. De la variedad de cuestiones promovidas por estos originales que no entraron en la edición de Amador de los Ríos (y que la crítica ha olvidado casi por completo, en consecuencia), escojo sólo una, que bien pronto, espero, aclarará su edición y estudio por José Anadón.

En el Proemio del libro VI de la Historia, que publicó Oviedo (Sevilla, 1535) y reprodujo Amador de los Ríos, se puede leer lo siguiente: "Entre tanto que el sol me tura, estoy agora en este año de la Natividad del Redemptor de mili e quinientos e cuarenta e ocho, dando orden..." En el autógrafo de la Huntington Library este pasaje no lleva la fecha de mill e quinientos e cuarenta $e$ ocho, sino, claramente, la de mil e quinientos e quarenta. Y como ha observado Anadón, esta última fecha, a su vez, ha sido cambiada sucesivamente a quarenta $e$ uno, quarenta e tres, quarenta e cinco, quarenta e siete, $\mathrm{y}$, por fin, 
quarenta $e$ ocho. El palimpsesto californiano nos revela etapas ignoradas en la redacción de la Historia general, que la retrotraen en nada menos que ocho años, en este caso particular. Claro está que al fundamentar una nueva cronología para la redacción de la Historia general, como lo hará José Anadón al llegar el momento, se replantea de nuevo toda la panorámica de la vida intelectual de Oviedo, $y$, como es bien sabido, ésta no siempre es fácilmente desligable de la vida física.

En resumidas cuentas, al llegar a este punto se debe haber hecho muy evidente la necesidad perentoria de replantear en sentido radical todos los problemas suscitados por la vida y la obra de Gonzalo Fernández de Oviedo. El estudio de la vida debe llevarnos de nuevo a los archivos, en particular al de Indias, como sugería, allá en 1898, José Toribio Medina. Y para abocarnos al estudio de la obra de Oviedo, el problema es aún más sencillo. Para estudiar esa obra en su conjunto, primero hay que publicarla in toto, ni más ni menos. El magistral libro de Antonello Gerbi, La naturaleza de las Indias Nuevas, debe servirnos de modelo y de aliciente en una empresa ardua si las hay. Una vez leido, admirado y asimilado el libro de Gerbi, debemos afanarnos todos en traer más luz, para iluminar con toda claridad posible la obra extraordinaria de ese madrileño sin par que fue Oviedo.

University of North Carolina.

Juan Bautista Avalle-Arce

\section{LAS VISIONES DE PETRARCA EN EL BARROCO ESPAÑOL (II): EN LA HUELLA DE FRAY LUIS}

El poeta ve visiones. Siempre la misma en figuras diferentes - gentil fiera destrozada por perros asesinos, nave estrellada en imprevisto escollo, fulminado laurel, aniquilada fuente, inmolado fénix, nueva Euridice- en cada visión de Petrarca revive Laura su último destino, en cada símbolo la muerte la transe para transfigurarla. La Canción CCCXXIII, lamento y loa a la amada arquetípica, es por esencia canción fúnebre, y como tal la imitaron en nuestro Siglo de Oro de Diego Dávalos, perulero, a Antonio López de Vega, hispanoportugués, de Don Francisco de Quevedo a Don Luis de Góngora ${ }^{1}$. Sin embargo, no fueron estas visiones solamente ocasión de laudatorios duelos. Desde su primera imitación española el poeta trueca su destino y propósito y los que fueran versos fúnebres se vuelven ejemplo y exhortación moral: cada visión un caso del desengaño.

En la imitación, muy hermosa, de Fray Luis de León coinciden por un lado la estructura formal de la canzone, el artificio de presentar en cada estrofa el avatar alegórico de una misma realidad, y por

1 Véase el trabajo previo a éste, "Las visiones de Petrarca en el Barroco español (1): Quevedo, López de Vega y Góngora", NRFH, 28 (1979), 287-305. 